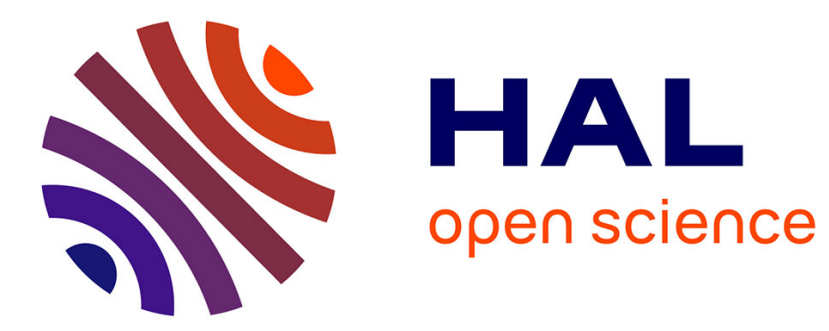

\title{
Wall friction and its effects on the density distribution in the compaction of pharmaceutical excipients
}

\author{
Abderrahim Michrafy, Moulay S. Kadiri, John A. Dodds
}

\section{To cite this version:}

Abderrahim Michrafy, Moulay S. Kadiri, John A. Dodds. Wall friction and its effects on the density distribution in the compaction of pharmaceutical excipients. Chemical Engineering Research and Design, 2003, 81 (A8), pp.946-952. 10.1205/026387603322482185 . hal-01680780

\section{HAL Id: hal-01680780 \\ https://hal.science/hal-01680780}

Submitted on 7 Nov 2019

HAL is a multi-disciplinary open access archive for the deposit and dissemination of scientific research documents, whether they are published or not. The documents may come from teaching and research institutions in France or abroad, or from public or private research centers.
L'archive ouverte pluridisciplinaire HAL, est destinée au dépôt et à la diffusion de documents scientifiques de niveau recherche, publiés ou non, émanant des établissements d'enseignement et de recherche français ou étrangers, des laboratoires publics ou privés. 


\title{
WALL FRICTION AND ITS EFFECTS ON THE DENSITY DISTRIBUTION IN THE COMPACTION OF PHARMACEUTICAL EXCIPIENTS
}

\author{
A. MICHRAFY, M. S. KADIRI and J. A. DODDS \\ Chemical Engineering Laboratory for Particulate Solids, UMR 2392, Ecole des Mines d'Albi, Albi, France
}

\begin{abstract}
$\mathrm{T}$ he effect of powder-die wall friction during the compaction of pharmaceutical excipients has been investigated for three modes of lubrication: lubricated die, nonlubricated die and with the lubricant mixed with the powder. Coulomb friction is assumed and the wall friction coefficient was evaluated from the transmission ratio (applied pressure/transmitted pressure), the transfer ratio (radial pressure/axial pressure) and the aspect ratio (height/diameter of tablet). The friction coefficient of three pharmaceutical excipients was measured with respect to the relative density of the tablet by means of an instrumented press. It was found that the behaviour of the friction depends on the powder and the lubrication mode. Mixing the powder with a lubricant reduces the friction with respect to that of the lubricated die, but the evolution of the friction coefficient with the densification is different. The effect of the wall friction on the axial density distribution in the tablet was investigated by experiment and by modelling. The model was based on Janssen-Walker analysis coupled with the Heckel equation. For comparison, only the single action compaction in a non-lubricated die was considered. It was found that the measured and predicted axial density decrease from the top to the bottom of the tablet. Moreover, the predicted and measured density had the same tendency, but different values. However, the analysis should not be applied to the compaction of the powder mixed with lubricant because no physical parameter for this mode of lubrication is taken into account in the model.
\end{abstract}

Keywords: compaction; wall friction; density; transmission ratio; transfer ratio; aspect ratio; modelling.

\section{INTRODUCTION}

The process of compaction of pharmaceutical powders and the resulting density of the tablet are mainly influenced by two major mechanisms: (i) interparticle friction and (ii) die wall friction. These are responsible for the non-uniform stress and strain distribution and contribute to create a density gradient in the tablet (Train, 1956), which in turn affects the mechanical properties and favours lamination in the decompression phase. The first mechanism (i) is often important in the first stage of consolidation and depends on the material hardness and the particle shape and size. However, movement between particles may continue beyond in the brittle material case. The ring shear tester or equivalent used to measure the inter-particle friction of powder (Schulze et al., 2001) cannot be applied to the die compaction where the inter-particle friction is related to the radial to axial stress ratio (Long, 1960). The other major source of friction in the compaction process is that resulting from the contact between die wall and powder. As friction is a tribological behaviour between two surfaces in contact, analysis may be made at both a microscopic or macroscopic scale. In the pharmaceutical industries lubricant powders are generally used to limit the effect of the die wall friction. However, these lubricants often cause an increase in the radial contact pressure on the die (Nelson, 1955) and may lead to excessive shear stresses in the tablet in the unloading step.

The object of this paper is to determine die wall friction during the compaction for three pharmaceutical excipients with and without die lubrication, and to estimate its effects on the axial density distribution in the tablet using an analytical predictive model. Furthermore, where the die wall friction coefficient is required for modelling compaction, this study may help to create a database of die wall friction coefficients and go some way towards a predictive analytical model of the axial density distribution.

The above-mentioned analytical model may be compared with results from a numerical analysis based on the finite element method, where the friction coefficient is input data. This is often assumed to be a constant value in simulations of the compaction process (Park and Kim, 2001; Shimosaka et al., 2001; Poquillon et al., 2002). However there are some experimental studies on the compaction of ceramic powders (Briscoe and Rough, 1998) and iron and steel powders (Wikman et al., 1997; Pavier and Dorémus, 1997; Cedergren et al., 2002) where the die wall friction has been measured. Measurements of the die wall friction 
assume Coulomb friction, and are based on two main techniques. In the first and most used method, the friction coefficient is evaluated from the axial stress on the upper and lower punches and the radial contact pressure (Wikman and Häggblad, 1997; Pavier and Dorémus, 1997; Cedergren et al., 2002; Li et al., 1996). The second technique measures the friction between a sliding slab representing the wall and the bottom of the compact. Here, the friction coefficient is calculated as the ratio of the measured frictional force on the moving slab to the normal force that is assumed to be equal to the applied compaction force in the lubricated die (see (Pavier and Dorémus, 1997) for the description the apparatus).

The first part of this paper concerns the measurement of die wall friction in the compaction of three pharmaceutical excipients (Avicel PH101, Avicel PH102 and Avicel PH105) with respect to the relative density of the tablet. The methodology used here is similar to the first technique briefly introduced above, but the data treatment is different. In the second part, the effect of the die wall friction on the axial density distribution is studied by experiment and modelling.

\section{EXPERIMENTAL PROCEDURE}

Three microcrystalline cellulose powders, often used as pharmaceutical excipients (Avicel PH101, Avicel PH102 and Avicel PH105 from J. Rettenmaier \& Söhne) were compacted with a reciprocating tablet press (Frogerais $\mathrm{OA})$. The particle sizes and densities of the powders were measured and are summarized in Table 1. The upper and lower punches of the press are cylindrical and flat faced, and were instrumented with a force transducer. The lower punch was fixed and the movement of the upper punch was measured with a displacement transducer (LVDT). The die section was $1 \mathrm{~cm}^{2}$ and its height $1 \mathrm{~cm}$. Thus, the apparent volume of the powder bed tested was taken to be $1 \mathrm{~cm}^{3}$.

Three modes of lubrication have been investigated: (s1) die lubricated with magnesium stearate; (s2) non-lubricated die; and (s3) where magnesium stearate lubricant is mixed with the powder to be compressed. The weight fraction of lubricant was $1 \%$. Powder and lubricant were mixed in a Turbula blender. Twelve tablets were compacted for each powder and each state of lubrication (s1, s2 and s3). The average compaction velocity was $31.25 \mathrm{~mm} \mathrm{~s}^{-1}$ (the average time of the compaction was $0.24 \mathrm{~s}$ and the average punch displacement was $7.5 \mathrm{~mm}$ ). Then, the estimated strain rate was $4.16 \mathrm{~s}^{-1}$. To avoid the die-filling problems at the start of the compression run, only the last six tablets were considered and only those tablets having the same mass were used. Each experiment was repeated twice for repeatability.

The axial stress on the upper and lower punch and the height of the compact were measured in each experiment.

Table 1. Powder characteristics (particle size and density).

\begin{tabular}{lccc}
\hline Powder & $\begin{array}{c}\text { Mean particle } \\
\text { size }(\mu \mathrm{m})\end{array}$ & $\begin{array}{c}\text { True density } \\
\rho_{\mathrm{t}}\left(\mathrm{g} \mathrm{cm}^{-3}\right)\end{array}$ & $\begin{array}{c}\text { Apparent } \\
\text { density } \\
\rho_{\mathrm{a}}\left(\mathrm{g} \mathrm{cm}^{-3}\right)\end{array}$ \\
\hline Avicel PH 105 & 20 & 1.514 & 0.23 \\
Avicel PH 101 & 50 & 1.503 & 0.29 \\
Avicel PH 102 & 90 & 1.599 & 0.31 \\
\hline
\end{tabular}

The apparent density was calculated from the measured mass and the height of the compact. The compact diameter was assumed to be equal to the internal diameter of the die, $11.28 \mathrm{~mm}$.

\section{THEORETICAL BACKGROUND}

During single action compaction of powder in a cylindrical rigid die, the axial force applied on the upper punch is transmitted as normal force $F_{\text {upp }}$ to the powder bed, causing its densification, and is transmitted as a radial force $F_{\text {rad }}$ to the die. Because of the existence of interparticle friction and the friction between the powder and the wall, $F_{\text {fric }}$, the force, $F_{\text {low }}$, transmitted to the lower punch is less than $F_{\text {upp. }}$.

As mentioned above, the major source of friction in the compaction process results from the friction between the powder under compaction and the die wall. The friction coefficient $\mu$ is defined as:

$$
\mu=\frac{F_{\text {fric }}}{F_{\text {rad }}}
$$

Several methods have been used to measure the radial force in compaction (Long, 1960; Leight et al., 1967; Es-Saheb, 1992), but it is difficult to access $F_{\text {fric }}$ by direct measurement. Hence, expression (1) does not lead to a practical method for measuring friction coefficient in a die compaction process. To determine the friction coefficient by an indirect method, the Janssen-Walker analytical model for compaction based on the 'method of differential slices' was used (Nedderman, 1992). This model predicts the value of the mean axial stress $\sigma_{h}$ at the depth $h$ from the top of the tablet by (see Figure 1):

$$
\sigma_{h}=\sigma_{\text {upp }} \exp \left(-\frac{4 \mu \alpha h}{D}\right)
$$

where $\sigma_{\text {upp }}=F_{\text {upp }} /\left(\pi D^{2} / 4\right)$ is the mean axial stress transmitted by the upper punch to the compact and $D$ the diameter of the die. The constant $\alpha$ can be related to the Janssen constant and the Walker distribution factor (Nedderman, 1992), and may be interpreted as the ratio of the radial to mean axial stress $\left(\alpha=\sigma_{r r} / \sigma_{h}\right)$.

If $h=H$, then $\sigma_{H}=\sigma_{\text {low }}$ Thus, from Equation (2), the friction coefficient may be then expressed as:

$$
\mu=\frac{\ln \left(\sigma_{\text {low }} / \sigma_{\text {upp }}\right)}{-4 \alpha H / D}
$$

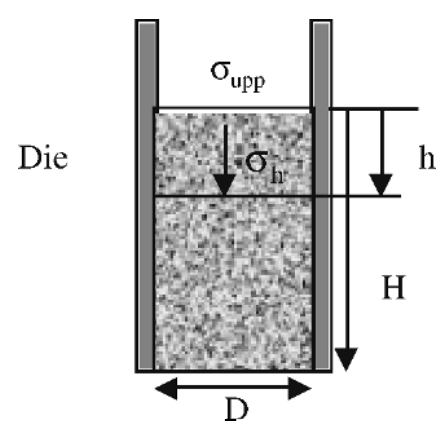

Figure 1. Mean axial stress at the height $h$ down from the top, for a given applied axial stress $\sigma_{\text {upp. }}$ 
Expression (3) gives an indirect and easy means of estimating the friction coefficient in die compaction. The friction coefficient may be obtained from the measurement of the transmission ratio $\sigma_{\text {low }} / \sigma_{\text {upp }}$, the transfer ratio $\alpha$ and the aspect ratio $H / D$. As friction depends on the state of the densification, it may be evaluated to respect the height of the tablet if $\alpha$ is known. As no instrumented die is available in our laboratory to access the radial pressure, the friction coefficient was determined from published values of $\alpha$ (Es-Saheb, 1992; Leight et al., 1967). However, these values were evaluated from the ratio $\sigma_{r r} / \sigma_{\text {upp }}$ instead of $\sigma_{r r} / \sigma_{h}$ because $\sigma_{h}$ is difficult to measure. Moreover, the transfer ratio depends in general on the density reached in the tablet and the strain rate of the compaction (Es-Saheb, 1992; Long, 1960). For a strain rate less than $10 \mathrm{~s}^{-1}$ the data published in Es-Saheb (1992) show that $\sigma_{r r} / \sigma_{\text {upp }}$ may be taken as being constant.

\section{WALL FRICTION COEFFICIENT RESULTS}

Following the experimental procedure presented above, the transmission ratio $\sigma_{\text {low }} / \sigma_{\text {upp }}$ and the aspect ratio $H / D$ were measured during powder compaction for each of the three states of lubrication described above. The friction coefficient was evaluated from Equation (3). The value of the transfer ratio $\alpha$ was fixed as 0.45 . This is the estimated value from the curve published in Es-Saheb (1992) for a strain rate less than $10 \mathrm{~s}^{-1}\left(4.16 \mathrm{~s}^{-1}\right.$ in our case).

\section{Results of the Friction Coefficient of the Compaction in a Lubricated Die}

From Equation (3), the resulting friction coefficient of the compaction in a lubricated die with the magnesium stearate was plotted vs. the relative density in Figure 2. The relative density was computed from the dimension of the compact in the die and the true density given in the Table 2.

As shown in Figure 2(a) and (b), the friction coefficient decreases in the first stage of the densification (relative density $\leq 0.5$ ) and tends towards an asymptotic value, which is independent of the increase in density. At the end of the compaction the friction coefficient was typically 0.18 for the Avicel PH101 and 0.16 for the Avicel PH102. However this behaviour is not found with Avicel PH105 (Figure 2c) as the friction coefficient decreases to 0.16 and then increases to 0.25 with the increase in the relative density. The increase of the friction coefficient of Avicel PH105 results from the transmission ratio $\sigma_{\text {low }} / \sigma_{\text {upp }}$ which increases for $\rho_{r} \leq 0.6$ and stabilizes at around $\sigma_{\text {low }} / \sigma_{\text {upp }} \approx 0.9$ in the range of relative density of $0.6-0.9$. To show that, the transmission ratio was plotted vs. the tablet height in the range of $2.5-3.7 \mathrm{~mm}$ (Figures 3 and 4). Therefore, from Equation (3) and for $\rho_{r} \geq 0.6$, the friction coefficient increases [because $\alpha$ and $D$ are constant, $\ln \left(\sigma_{\text {low }} / \sigma_{\text {upp }}\right)$ is constant for $\rho_{r} \geq 0.6$ and $H$ decreases]. In contrast, the transmission ratio of the other powders (PH101 and PH102) increases towards 1.0 with the decrease of the tablet height. Moreover, in this case, $\ln \left(\sigma_{\text {low }} / \sigma_{\text {upp }}\right) /(-4 \alpha H / D)$ continues to decrease.
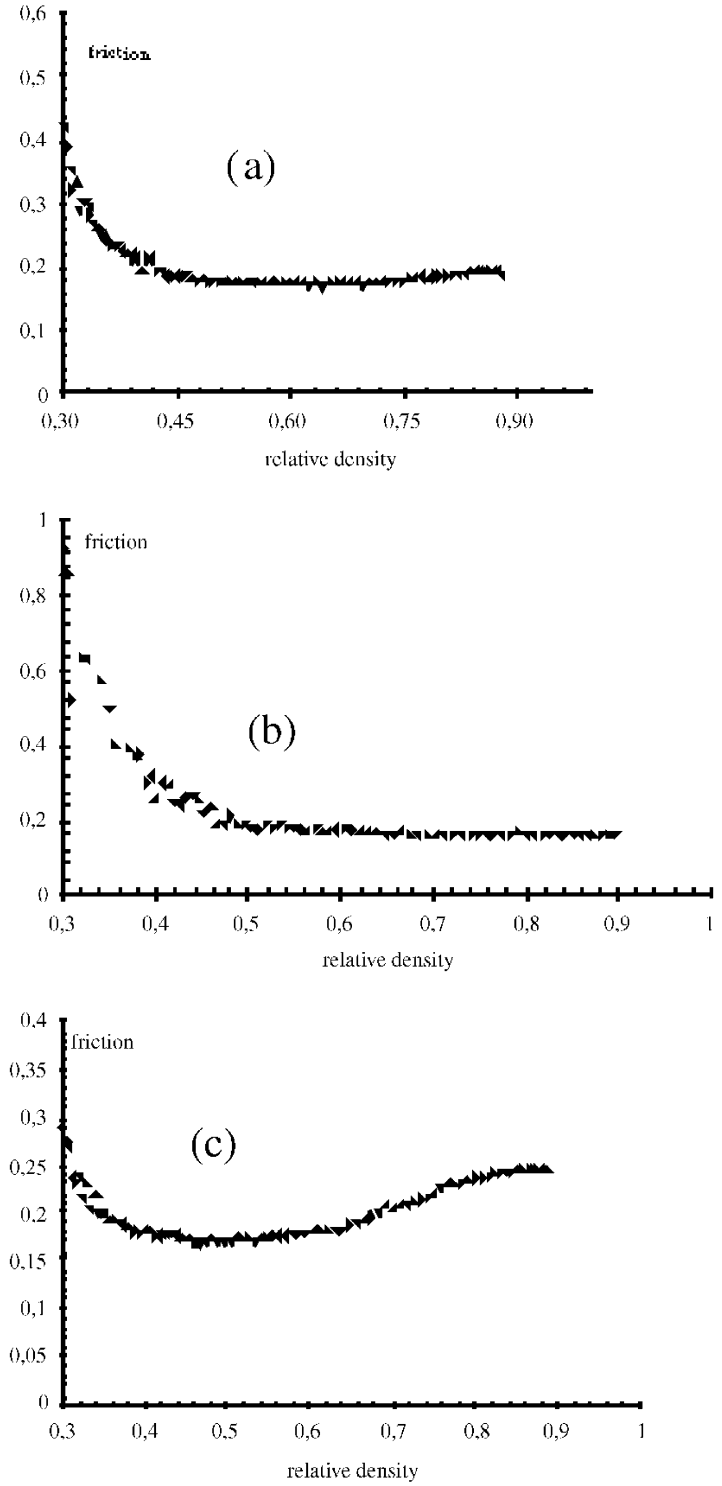

Figure 2. Friction coefficient vs. relative density: compaction in lubricated die. (a) Avicel PH101; (b) Avicel PH102; (c) Avicel PH105.

\section{Results of the Friction Coefficient of the compaction in Non-lubricated Die}

The results for the friction coefficient in compaction with a non-lubricated die are plotted in Figure 5. For the Avicel PH102 and PH105 (Figure 5b and c) the friction coefficient decreases in the first stages of densification $\left(\rho_{r} \leq 0.7\right)$ and then stabilizes as the relative density increases further. The

Table 2. Parameters of tablets compacted up to $\sigma_{\mathrm{w}}=10 \mathrm{MPa}$.

\begin{tabular}{lccccc}
\hline $\begin{array}{l}\text { Tablet } \\
\text { number }\end{array}$ & 1 & 2 & 3 & 4 & 5 \\
\hline $\begin{array}{c}\text { Diameter } \\
(\mathrm{mm})\end{array}$ & 11.29 & 11.29 & 11.29 & 11.29 & 11.29 \\
$\begin{array}{c}\text { Thickness } \\
(\mathrm{mm})\end{array}$ & 7.32 & 7.33 & 7.36 & 7.33 & 7.32 \\
$\begin{array}{c}\text { Mass } \\
(\mathrm{g})\end{array}$ & 0.545 & 0.549 & 0.551 & 0.549 & 0.547 \\
$\begin{array}{c}\text { Relative } \\
\text { density }\end{array}$ & 0.465 & 0.468 & 0.467 & 0.468 & 0.467 \\
\hline
\end{tabular}




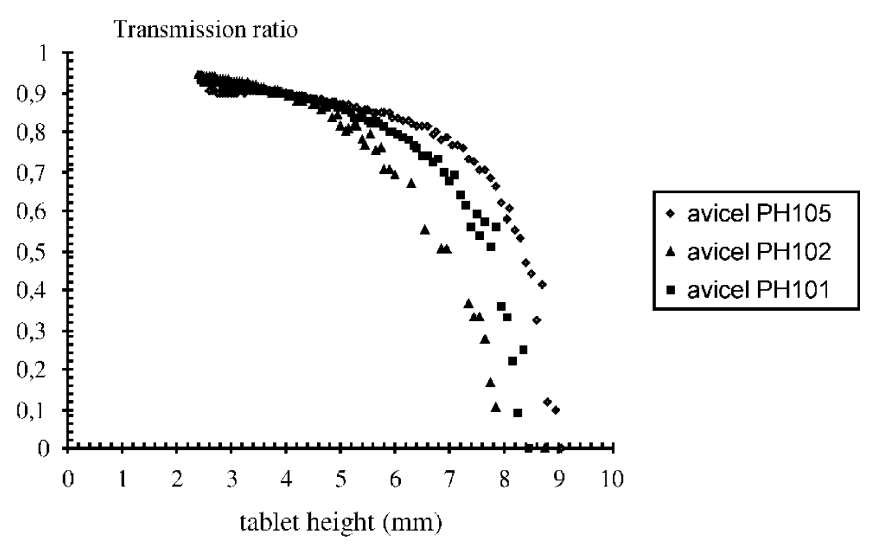

Figure 3. Transmission ratio vs. tablet height (compaction in lubricated die).

asymptotic value reached was 0.38 for Avicel PH102 and 0.3 for Avicel PH105. However, the friction behaviour of Avicel PH101 (Figure 5a) seems to be slightly different in that the friction coefficient decreases down to 0.27 and increases to a constant value of 0.4 . This behaviour is due to the fact that the tablet height continues to decrease while the transmission ratio approaches a constant $\sigma_{\text {low }} /$ $\sigma_{\text {upp }} \approx 0.85$ as shown in Figure 6. This happens when the relative density reaches 0.6 . Therefore, from Equation (3), the friction coefficient increases $[\alpha, D$ are constants, $H$ decreases and $\ln \left(\sigma_{\text {low }} / \sigma_{\text {upp }}\right)$ is constant for $\left.\rho_{r} \geq 0.6\right]$. However, in the case of Avicel PH102 and PH105, the transmission ratio increases continuously with the decrease of the tablet height (Figure 6$)$. Moreover, $\ln \left(\sigma_{\text {low }} / \sigma_{\text {upp }}\right) /$ $(-4 \alpha H / D)$ continues to decrease.

\section{Results for the Friction Coefficient of the Compaction of Powder Mixed with Lubricant}

The friction coefficient for the compaction of powders lubricated with the magnesium stearate $(1 \mathrm{wt} \%)$ is plotted in Figure 7. The behaviour is different from one powder to another. Thus, the friction coefficient of Avicel PH101 (Figure 7a) decreases and increases slightly around the mean value of 0.2. However, for Avicel PH102 it increases continuously up to a value of 0.2 (Figure $7 \mathrm{~b}$ ) and then decreases to a value of 0.15 for Avicel PH105 (Figure 7c) without a tendency to converge towards a constant value.

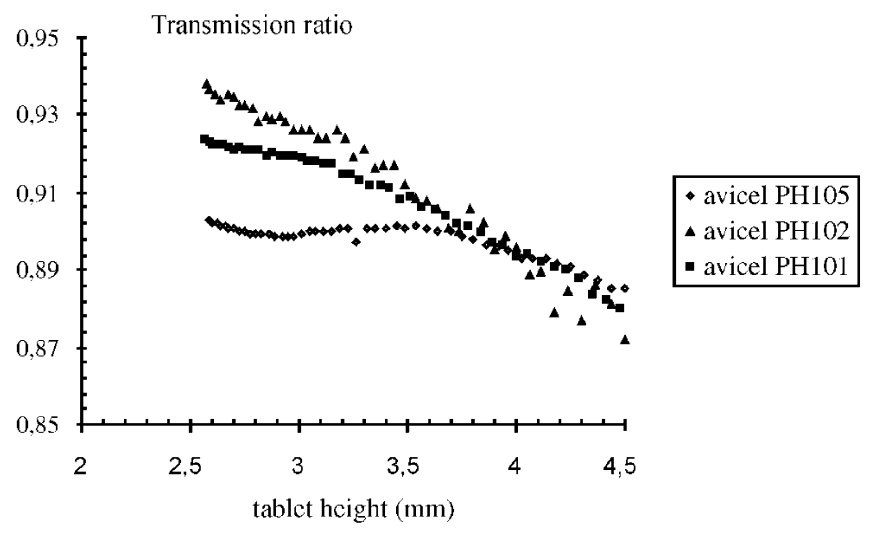

Figure 4. Transmission ratio vs. tablet height (compaction in lubricated die; tablet height range $2.5-4.5 \mathrm{~mm}$ ).
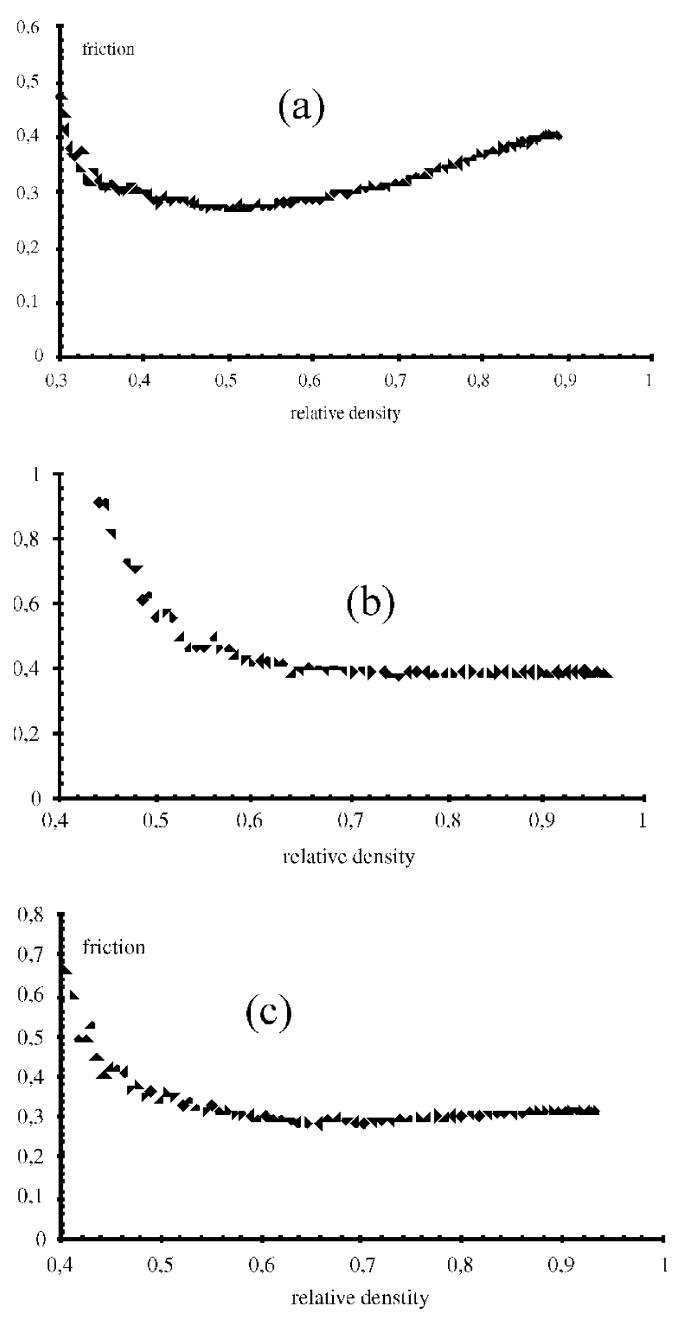

Figure 5. Friction coefficient vs. relative density: compaction in unlubricated die. (a) Avicel PH101; (b) Avicel PH102; (c) Avicel PH105.

These results show a complex behaviour in friction when the lubrication is ensured by mixing the lubricant with the powder. Mechanisms by which there is expulsion of the lubricant towards the die wall or its capture in the compact depend on several parameters such particle size, level of the applied stress, cohesion between the powder and the lubricant, behaviour of the lubricant in contact with the die wall, etc. However, mixing of powder with lubricant does contribute to reduction of the die wall friction coefficient.

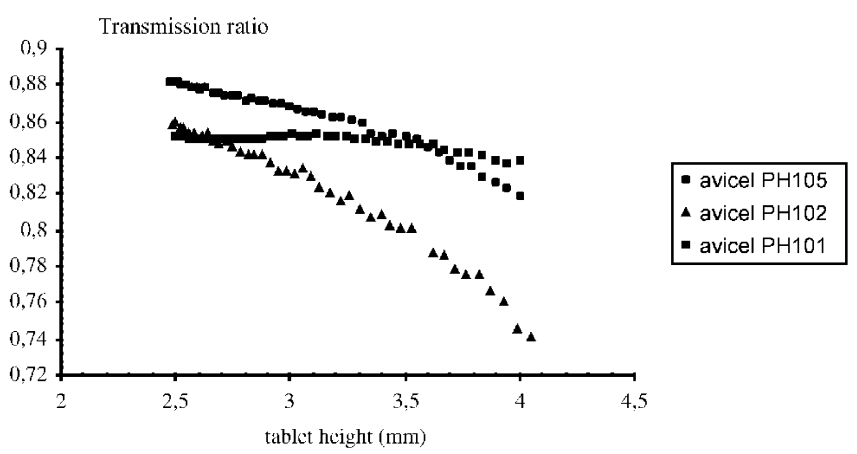

Figure 6. Transmission ratio vs. tablet height (compaction in non-lubricated die; tablet height range $2.5-4 \mathrm{~mm}$ ). 

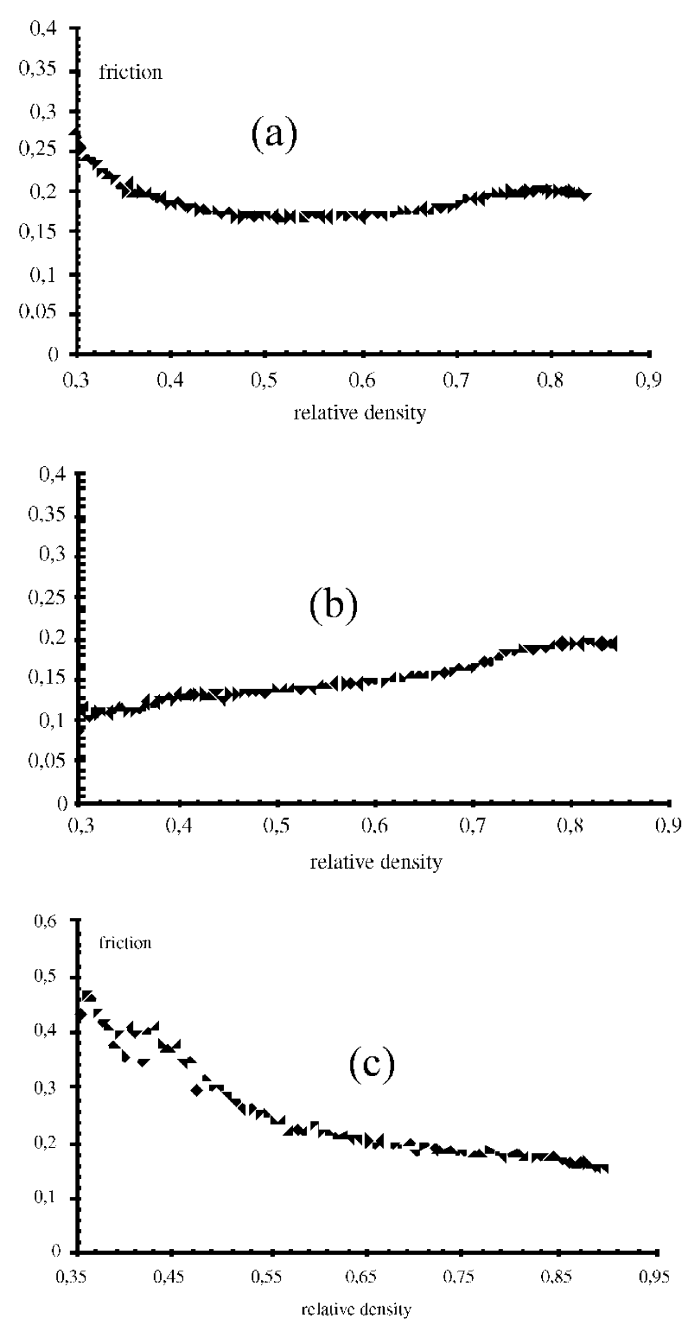

Figure 7. Friction coefficient vs. relative density: powder lubricated with stearate of magnesium (1 wt\%) and unlubricated die. (a) Avicel PH101; (b) Avicel PH102; (c) Avicel PH105.

\section{ANALYTICAL ANALYSIS OF THE AXIAL DENSITY DISTRIBUTION}

\section{Analytical Density-Axial Stress Relationship}

In pharmaceutical compaction, the most commonly used equation to predict the pressure for a required density is the empirical Heckel equation, which may be expressed as:

$$
\ln \left[\frac{1}{1-\rho_{r}}\right]=A+K \sigma_{\text {upp }}
$$

where $\rho_{r}$ is the relative density of the compact, and $A$ and $K$ are constants which may be determined from experimental data. Equation (5) seems reasonable, considering the tablet as a homogeneous media. However this is not the case in the powder compaction in a die where the transmission load to the particles occurs in a non-homogeneous way. The density being a local physical variable, its values depend on the strain (or stress) which is function of the boundary conditions applied to the powder. In order to analyse the effect of the axial variation in stress on the axial density distribution, the approximate method of differential slices was applied (Nedderman, 1992). The tablet with height $H$ was subdivided into slices assuming the density to be constant in each slice. For each slice the relationship (5) may be expressed, using $\sigma_{h}$ from the Equation (2), as:

$$
\ln \left[\frac{1}{1-\rho_{r}(h)}\right]=A+K \sigma_{\text {upp }} \exp \left(-\frac{4 \mu \alpha h}{D}\right)
$$

where $h$ is the distance from the centre of the slice to the top of the tablet (see Figure 8 ) and $\mu$ defined by Equation (3) is a constant for a given $H$.

Using Equation (3), Equation (6) may be written as:

$$
\ln \left[\frac{1}{1-\rho_{r}(h)}\right]=A+K \sigma_{\text {upp }} \exp \left[\frac{\ln \left(\sigma_{\text {low }} / \sigma_{\text {upp }}\right) h}{H}\right]
$$

In this form of Equation (7), $A, K$ and $\ln \left(\sigma_{\text {low }} / \sigma_{\text {upp }}\right)$ are constants and may be fitted from the measured data. Thus, the relative density of a slice at the height $h$ from the top is explicitly expressed as a function of the transmission ratio $\sigma_{\text {low }} / \sigma_{\text {upp }}$, the ratio $h / H$ and constants $A$ and $K$. Moreover, if the ratio $\sigma_{\text {low }} / \sigma_{\text {upp }} \neq 1$, the relative density is such that $\ln \left[1 /\left(1-\rho_{r}(h)\right]\right.$ decreases exponentially from $A+K \sigma_{\text {upp }}$ to $A+K \sigma_{\text {low }}$ with resspect to $h$. However in perfect lubrification $(\mu=0)$, the transmission ratio $\sigma_{\text {low }} / \sigma_{\text {upp }}$ is typically equal to 1 and Equation (7) gives the Heckel Equation (5). Thus, the friction effect on the axial density is taken into account in the transmission ratio $\sigma_{\text {low }} / \sigma_{\text {upp }}$ that is lower than unity.

\section{Axial Density Measurements}

Researchers have used a number of techniques to characterize the density distribution in compacts. These include NMR radioscopy (Nebgen, 1995), auto-radiography (Macleod and Marshall, 1997), or a coloured layer technique (Özkan and Briscoe, 1990). In this work, a simple procedure was used to investigate the axial density distribution in tablet of microcrystalline cellulose (Avicel PH102).

\section{Experimental procedure}

The procedure is as follows where the compaction was made using a standard instrumented press (the upper and the lower punch were instrumented with a force sensor and the upper punch displacement measured with an LVDT sensor). The velocity of the compaction was $0.16 \mathrm{~mm} \mathrm{~s}^{-1}$.

\section{Step 1: pre-compaction up to $10 \mathrm{MPa}$ of thin and} similar tablets in a lubricated die

Five flat and thin tablets having the same weight were compacted in a lubricated cylindrical die with a moderate

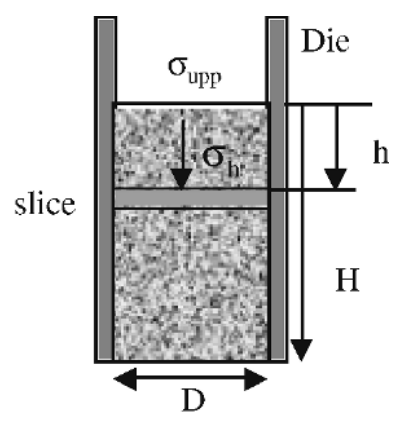

Figure 8. Definition of the symbols used. 


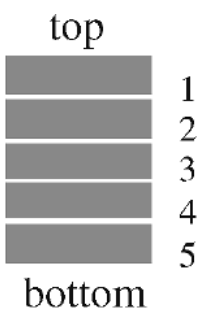

Figure 9. Order of numeration of the slices.

load $\sigma_{\mathrm{w}}=10 \mathrm{MPa}$. The die diameter was $11.28 \mathrm{~mm}$ and the lubricant used was magnesium stearate. Once ejected, the height, diameter, mass and density of the tablets were measured. Because of the elastic recovery effect, the diameter of tablets was typically $11.29 \mathrm{~mm}$ instead of $11.28 \mathrm{~mm}$. This experiment was repeated twice and results were the same. The results of this first step are summarized in Table 2 .

\section{Step 2: compaction of the thin tablets together in} a non-lubricated die

The prepared tablets are numbered $1-5$ as in Figure 9 and placed in a non-lubricated cylindrical die (diameter $11.29 \mathrm{~mm}$ ) and compacted up to $\sigma_{\max }=60 \mathrm{MPa}$. The tablet made in this way was named 'tablet_5'. Figure 10 shows curves of the compaction of tablet_5 and the compaction of the same mass of powder as tablet_5. This result indicates that the compaction of the pre-compacted tablets was similar to the compaction of the equivalent mass of powder. The only difference was at the beginning where the behaviour was linear up to $10 \mathrm{MPa}$, which was the applied stress for the pre-compacted tablets. After ejecting tablet_5, its characteristics were measured (diameter $=11.33 \mathrm{~mm}$, height $=23.68 \mathrm{~mm}$, mass $=2.75 \mathrm{~g}$, relative density $=0.72$ ). Then thin tablets were separated. There was no apparent damage of the contact faces. However, this operation was not possible for applied pressures greater than $60 \mathrm{MPa}$. The characteristics of the five thin tablets (thickness, diameter, mass and density) were also measured. This experiment was repeated twice with identical results. These are summarized in Table 3.

\section{Step 3: determination of the constants}

\section{$A, K$ and $\ln \left(\sigma_{\text {low }} / \sigma_{\text {upp }}\right)$}

The objective of this step is to compare the measured (Table 3) and calculated [Equation (7)] relative density for

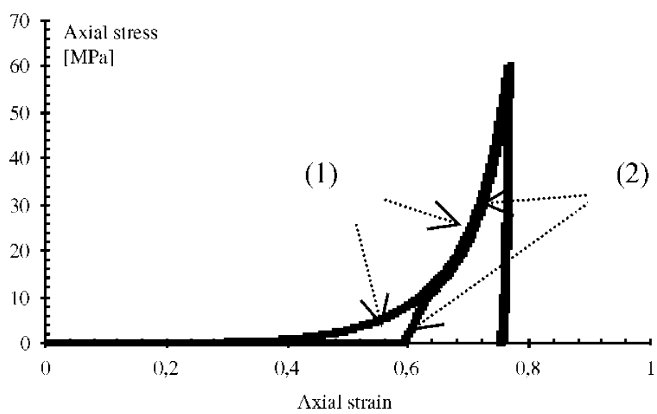

Figure 10. Axial stress vs. axial strain: (1) compaction of $2.75 \mathrm{~g}$ of powder; (2) compaction of precompacted thin tablets together (total mass $=2.75 \mathrm{~g}$ ); (Avicel PH102).
Table 3. Experimental data of the separated tablets after compacting them together.

\begin{tabular}{lccccc}
$\begin{array}{l}\text { Table } \\
\text { number }\end{array}$ & 1 & 2 & 3 & 4 & 5 \\
\hline $\begin{array}{c}\text { Diameter } \\
(\mathrm{mm})\end{array}$ & 11.33 & 11.33 & 11.33 & 11.33 & 11.33 \\
$\begin{array}{c}\text { Thickness } \\
(\mathrm{mm})\end{array}$ & 4.62 & 4.70 & 4.75 & 4.79 & 4.82 \\
$\begin{array}{c}\text { Mass } \\
(\mathrm{g})\end{array}$ & 0.545 & 0.549 & 0.551 & 0.549 & 0.547 \\
$\begin{array}{c}\text { Relative } \\
\text { density }\end{array}$ & 0.731 & 0.724 & 0.719 & 0.711 & 0.704 \\
\hline
\end{tabular}

each thin tablet. To fit the mechanical parameters $A$ and $K$ in Equation (7), the same powder mass as tablet_5 (2.75 g) was compacted up to $\sigma_{\text {upp }}=60 \mathrm{MPa}$. The transmitted pressure to the lower punch was $\sigma_{\text {low }}=49.12 \mathrm{MPa}$. Therefore, $\ln \left(\sigma_{\text {low }} / \sigma_{\text {upp }}\right)$ was equal to -0.2 . From the axial pressure and axial strain data, the curve $\ln \left[1 /\left(1-\rho_{r}\right)\right]$ vs. the applied pressure was plotted in Figure 11. The linear part of this curve gives the constant $A$ and $K$ of Equation (5): $A=0.56$ and $K=0.016 \mathrm{MPa}^{-1}$.

\section{Experimental and predictive results of}

the axial density distribution

The distance $h$ from the top of the tablet to the centre of the tablets $1-5$ was $2.31,6.97,11.69,16.46$ and $21.27 \mathrm{~mm}$. The relative density of tablets was calculated by using the predictive model [Equation (7)]. The relative density, based on the Heckel equation [Equation (5)] was also calculated.

Figure 12 shows relative densities obtained by experiment for the compaction of the microcrystalline cellulose (avicel PH102) in non-lubricated die (Table 3) and those calculated

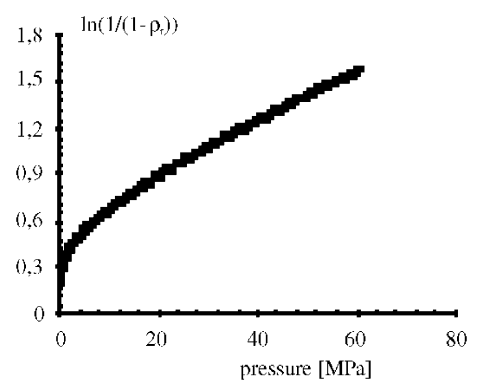

Figure 11. Heckel curve: compaction of $2.75 \mathrm{~g}$ of powder (Avicel PH102).

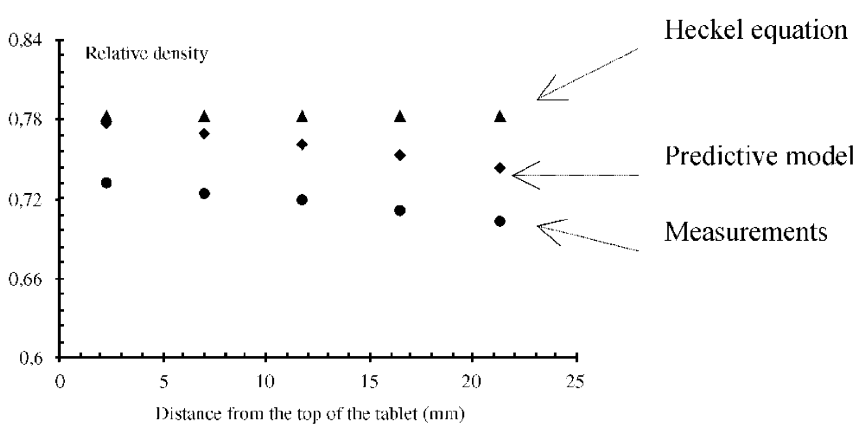

Figure 12. Measured and predicted values of the relative density at different tablet height. Compaction of powder (Avicel PH102) in non-lubricated die. 
using Equations (5) and (7). It is shown that the measured density decreases from the top to the bottom. The computed values show the same tendency but do not predict the experimental measurements.

\section{CONCLUSION}

The influence of the mode of lubrication on the wall friction coefficient has been investigated for three pharmaceutical excipients by means of an instrumented tablet press. The friction coefficient was obtained by an indirect method based on the measurement of the transmission ratio, the transfer ratio and the aspect ratio. In the case of lubricated and non-lubricated dies the friction coefficient decreases continuously (or decreases and increases) with the increase in the relative density. Values converge towards an asymptote. The friction behaviour of the compaction of a powderlubricant mixture (magnesium stearate) seems too complex to interpret. The effects found may be attributable to expulsion of the lubricant towards the die wall and may depend on the contribution of various parameters such particle size, level of the applied stress and the powder compressibility. However, this mode of lubrification does reduce the friction coefficient and is more practical at high production rates than the die lubrication mode.

The effect of wall friction on the axial distribution density in the tablet was studied by experiment and modelling. Only the compaction in a non-lubricated die was considered in this work. Although, the case of lubricated die may studied with the same methodology. It was shown that the measured axial density decreases from the top to the bottom of the tablet. A model based on the Janssen-Walker analysis, coupled with the Heckel equation, was applied to predict the density in the tablet. The predicted and measured density had the same tendency, but different values. However, the analysis should not be applied to the compaction of powder mixed with lubricant because no physical parameter for this mode of lubrication is taken into account in this model.

\section{NOMENCLATURE}

$F_{\text {fric }}$
$F_{\text {rad }}$
$F_{\text {upp }}$
$\sigma_{\text {upp }}$
$\sigma_{\text {low }}$
$\sigma_{r r}$
$\sigma_{h}$
$\sigma_{\mathrm{w}}$
$\mu$
$D$
$H$

\section{wall friction force}

radial force at the die wall

force on the upper punch

axial stress on the upper punch

axial stress on the lower punch

radial stress at the die wall

mean stress at the height $h$ from the top of tablet

applied stress to pre-compact thin tablets

friction coefficient

diameter of the die

tablet thickness

\section{REFERENCES}

Briscoe, B.J. and Rough, S.L., 1998, The effects of the wall friction in powder compaction, Colloids Surf A Physicochem Eng Asp, 137: 103-116.

Cedergren, J., Sorensen, N.J. and Bergmark, A., 2002, Three-dimensional analysis of the compaction of metal powder, Mech Mater, 34: 43-59.

Es-Saheb, M.H., 1992, Uniaxial strain rate effects in pharmaceutical powders during cold compaction, J Mater Sci, 27: 4151-4159.

Leight, S., Carless, J.E. and Burt, B.W., 1967, Compression characteristics of some pharmaceutical materials, J Pharm Sci, 56: 888-892.

Li, Y., Liu, H. and Rockabrand, A., 1996, Wall friction and lubrication during the compaction of coal logs, Powder Technol, 87: 259-267.

Long, W.M., 1960, Radial pressures in Powder compaction, Powder Metall, 6: 73 .

Macleod, H.M. and Marshall, K., 1977, Powder Technol, 16: 107-122.

Nebgen, G., Gross, D., Lehmann, V. and Muller, F., 1995, 1H-NMR microscopy of tablets, J Pharm Sci, 84: 283-291.

Nedderman, R.M., 1992, Statics and Kinematics of Granular Materials (Cambridge University Press, Cambridge).

Nelson, E., 1955, J Am Pharm Assoc Sci Ed, Vol 44: 494.

Özkan, N. and Briscoe, B.J., 1977, Characterization of die-pressed Green compacts, Journal of the European Ceramic Society, 17: 697-711.

Park, H. and Kim, K.T., 2001, Consolidation behavior of SiC powder under cold compaction, Mater Sci Eng, A229: 116-124.

Pavier, E. and Dorémus, P., 1997, Friction behavior of an iron powder investigated with two different apparatus, in Proceedings of International Workshop on Modeling of Metal Powder Forming Processes, Grenoble, France, 21-23 July 1997.

Poquillon, D., Lemaitre, J., Baco-Carles, V., Tailhades, Ph. and Lacaze, J., 2002, Cold compaction of iron powders-relations between powder morphology and mechanical properties, Part I: powder preparation and compaction, Powder Technol, 126.

Schulze, D., Heinrici, H. and Zetzener, H., 2001, The ring shear tester as a valuable tool for silo design and powder characterization, Powder Handling Proc, 13(1).

Shimosaka, A., Hayashi, K., Shirakawa, Y. and Hidaka, J., 2001, Estimation of stress distribution arising in a powder bed during compaction by FEM considering anisotropic parameters, KONA, 19: 262-272.

Train, D., 1956, An investigation into the compaction of powders, J Pharm Pharmacol, 8: 744-761.

Wikman, B., Häggblad, H.-A. and Oldenburg, M., 1997, Modeling of powder-wall friction for simulation of iron powder pressing, in Proceedings of International Workshop on Modeling of Metal Powder Forming Processes, Grenoble, France, 21-23 July 1997.

\section{ADDRESS}

Correspondence concerning this paper should be addressed to Dr A. Michrafy, Chemical Engineering Laboratory for Particulate Solids, UMR 2392, Ecole des Mines d'Albi, Campus Jarlard, 81000 Albi, France. E-mail: michrafy@entimac.fr 